\title{
An Integrated Individual Environmental Exposure Assessment System for Real-Time Mobile Sensing in Environmental Health Studies
}

\author{
Jue Wang ${ }^{1,2}\left(\mathbb{D}\right.$, Lirong Kou ${ }^{3}$, Mei-Po Kwan ${ }^{4,5, * \mathbb{D}}$, Rebecca Marie Shakespeare ${ }^{6} \mathbb{D}$, Kangjae Lee ${ }^{7}$ (D) \\ and Yoo Min Park ${ }^{8}$ (D)
}

check for

updates

Citation: Wang, J.; Kou, L.; Kwan, M.-P.; Shakespeare, R.M.; Lee, K.;

Park, Y.M. An Integrated Individual Environmental Exposure Assessment System for Real-Time Mobile Sensing in Environmental Health Studies. Sensors 2021, 21, 4039. https:// doi.org/10.3390/s21124039

Academic Editors: David Niederseer and Bernd Resch

Received: 22 May 2021

Accepted: 6 June 2021

Published: 11 June 2021

Publisher's Note: MDPI stays neutral with regard to jurisdictional claims in published maps and institutional affiliations.

Copyright: (c) 2021 by the authors. Licensee MDPI, Basel, Switzerland. This article is an open access article distributed under the terms and conditions of the Creative Commons Attribution (CC BY) license (https:// creativecommons.org/licenses/by/ $4.0 /)$.
1 Department of Geography, Geomatics and Environment, University of Toronto Mississauga, Mississauga, ON L5L 1C6, Canada; gis.wang@utoronto.ca

2 Department of Geography and Planning, University of Toronto, Toronto, ON M5S 1A1, Canada

3 School of Tourism Management, Sun Yat-sen University, Guangzhou 510275, China; koulr3@mail.sysu.edu.cn

4 Department of Geography and Resource Management and Institute of Space and Earth Information Science, The Chinese University of Hong Kong, Shatin, Hong Kong, China

5 Department of Human Geography and Spatial Planning, Utrecht University, 3584 CB Utrecht, The Netherlands

6 Department of Urban and Environmental Policy and Planning, Tufts University, Medford, MA 02155, USA; rebecca.shakespeare@tufts.edu

7 School of Civil and Environmental Engineering, Yonsei University, Seoul 03722, Korea; kkooring@uos.ac.kr

8 Department of Geography, Planning, and Environment, East Carolina University, Greenville, NC 27858, USA; parky19@ecu.edu

* Correspondence: mpkwan@cuhk.edu.hk

\begin{abstract}
The effects of environmental exposure on human health have been widely explored by scholars in health geography for decades. However, recent advances in geospatial technologies, especially the development of mobile approaches to collecting real-time and high-resolution individual data, have enabled sophisticated methods for assessing people's environmental exposure. This study proposes an individual environmental exposure assessment system (IEEAS) that integrates objective real-time monitoring devices and subjective sensing tools to provide a composite way for individualbased environmental exposure data collection. With field test data collected in Chicago and Beijing, we illustrate and discuss the advantages of the proposed IEEAS and the composite analysis that could be applied. Data collected with the proposed IEEAS yield relatively accurate measurements of individual exposure in a composite way, and offer new opportunities for developing more sophisticated ways to measure individual environmental exposure. With the capability to consider both the variations in environmental risks and human mobility in high spatial and temporal resolutions, the IEEAS also helps mitigate some uncertainties in environmental exposure assessment and thus enables a better understanding of the relationship between individual environmental exposure and health outcomes.
\end{abstract}

Keywords: individual environmental exposure; portable sensors; environmental health; health geography

\section{Introduction}

The effects of environmental exposure on human health have been investigated by scholars for decades. There is growing evidence indicating the association between environmental exposure and health outcomes or behaviors: obesity and cardiovascular diseases are correlated with the food environment [1,2]; health-promoting physical activity was affected by green space [3,4]; certain environmental exposures could lead to tobacco and substance drug use [5-7]; stress, depression and other mental health disorders are related to neighborhood contexts [8,9]. However, the associations between environmental exposures and health were often found to be inconsistent [10-12]. 
Recent studies have identified several fundamental problems that could contribute to such inconsistency [13-15]. Among the limitations of past studies is their tendency to adopt a static approach to assessing human exposure to environmental risks by assuming that residential neighborhoods are the most relevant contextual areas that affect individual exposure $[10,16]$. However, residential neighborhoods may not accurately capture the true geographic contexts that exert influences on people's health because people move around to perform daily activities and thus are also exposed to environmental risks in non-residential neighborhoods $[17,18]$. In addition, the temporal dynamics of environmental risks add to the complexity of environmental exposure assessment. For instance, studies have shown that using hourly air pollution concentrations improves the accuracy in assessments of the relationships between environmental exposure and health outcomes, compared with using daily averages of air pollution concentrations [19].

Further, the neglect of human mobility and the temporal variations of environmental risks can lead to erroneous results due to two methodological problems: the uncertain geographic context problem (UGCoP) and the neighborhood effect averaging problem (NEAP) $[16,20]$. The UGCoP, involving both spatial and temporal uncertainties, arises because of our limited knowledge of the true geographic contexts for assessing their health effects. Spatial uncertainties are due to the imprecise spatial configuration of the contextual areas that influence human health. Temporal uncertainties arise because the timing and duration in which individuals are exposed to environmental risks are ignored. The UGCoP may have confounding effects on the relationships between environmental exposure and health outcomes, leading to inferential errors. The NEAP refers to the tendency of individual mobility-dependent exposures (e.g., noise or air pollution) towards the mean value of the participants or population of a study area when people's daily mobility is ignored. Because of the NEAP, the health impacts of individual environmental exposures observed with traditional residence-based assessments may be erroneous [11,16].

To mitigate the UGCoP and the NEAP, recent studies have increasingly adopted a dynamic approach to assessing individual environmental exposure [11,21,22], which is individual-based and person-specific, incorporating human mobility and spatiotemporal variations in environmental risks [21,22]. It is based on the premise that exposure to environmental risks is inextricably related to human movement patterns at various spatial and temporal scales. It considers not just where people live but also where they visit and when and how much time they spend at each activity location [20]. Thus, the measurement of individual environmental exposure may need to shift from residential neighborhoods to include multiple geographic contexts of individuals' everyday life [19] for better environmental exposure assessment.

Advances in geospatial technologies, especially the development of mobile approaches to collecting real-time and high-resolution individual data, have enabled many new methods for examining the health effects of environmental exposure [4,15,23-25]. Most of these innovative approaches involve the use of GPS tracking and portable or mobile sensing (e.g., noise and air pollutant sensors). Employing these objective exposure monitoring methods would not only provide more accurate assessments of individual exposure but also help address the major methodological issues and limitations of past studies $[19,26]$. However, focusing only on objective environmental exposure may ignore the differences between people's perceptions of the same objective environment. For example, differences in individuals' perceived exposure to noise and greenspace could lead to variations in individual responses to the same levels of environmental exposure.

Further, different environmental factors may interact, and these interactions may have complex health impacts that may be different from those of each individual factor or those from adding the separate effects of these individual factors. Environmental factors influence human health through complex interactions and mediating pathways that may render their individual impact on human health difficult to ascertain. For instance, green space exposure may increase people's physical activity and mitigate pollution levels by removing pollutants from the air, while green space is also a source of pollen and may aggravate 
allergies and increase particulate matter counts. We not only need to measure people's exposure to individual environmental factors over space and time accurately but also need to consider their complex interactions and the mediating pathways. In another example, it is possible that exposure to high noise levels and high pollution levels simultaneously could aggravate their individual health impacts. Thus it is necessary to integrate objective environmental exposure monitoring and subjective environmental exposure sensing for individual environmental exposure assessment in environmental health studies.

This paper proposes an individual environmental exposure assessment system (IEEAS) that integrates objective environmental exposure monitoring devices (such as portable GPS trackers, air pollution sensors, and noise sensors) and subjective environmental exposure sensing tools (such as ecological momentary assessment) to provide a thorough picture of individual exposure. The integration of these real-time data related to human mobility and experience provides fine-grained, spatially, and temporally situated data about environmental contexts and individual activities and emotions. The IEEAS was first implemented in an exploratory pilot project in Chicago with a small sample ( 45 participants). The focus of this paper is on implementing the IEEAS and seeing how well it works. The primary purpose of the paper is thus not to present a full-scale research project (e.g., reporting research results in detail) but to illustrate how the system works based on this pilot project. Subsequently, the IEEAS developed in the Chicago pilot project was used in Beijing, China, to collect a second dataset from 120 participants. The paper thus draws from both the Chicago and Beijing projects to illustrate the kind of findings that can be obtained from using the IEEAS and the potential of the IEEAS for individual environmental exposure and health studies. We discuss several selected results to illustrate the advantages of the proposed IEEAS and the possible composite analysis. Both the Chicago project and the Beijing project, although exploratory in nature, are among the few studies to date that simultaneously collected real-time data on people's exposures to two environmental risk factors (i.e., air pollution and noise). The proposed assessment system presents new opportunities for deploying more sophisticated methods for measuring individual environmental exposure and thus promotes a better understanding of the relationship between individual exposure and health outcomes.

\section{Materials and Methods}

This paper proposes an integrated individual environmental exposure assessment system (IEEAS) that combines data from objective environmental exposure monitoring devices and subjective environmental exposure sensing tools. Figure 1 illustrates these key components of the IEEAS, additional sociodemographic information, environmental context GIS data, as well as device monitoring, data encryption, and data transfer.

\subsection{Integrated Objective Environmental Exposure Monitoring Devices}

The development of Global Positioning System (GPS) technologies and portable or mobile environmental sensors provides affordable ways for assessing individual realtime movement patterns and environmental exposure [27,28]. GPS technologies enable researchers to collect high-resolution spatiotemporal data of individuals' locations and travel routes $[29,30]$. With their recent advances, GPS and portable environmental sensors are increasingly integrated and used together in recent research to collect high-resolution spatiotemporal data of person-specific real-time environmental exposure. Examples of integrated sensor systems include N-Smart [31], Common Sense [32], MobGeoSen [33]. 


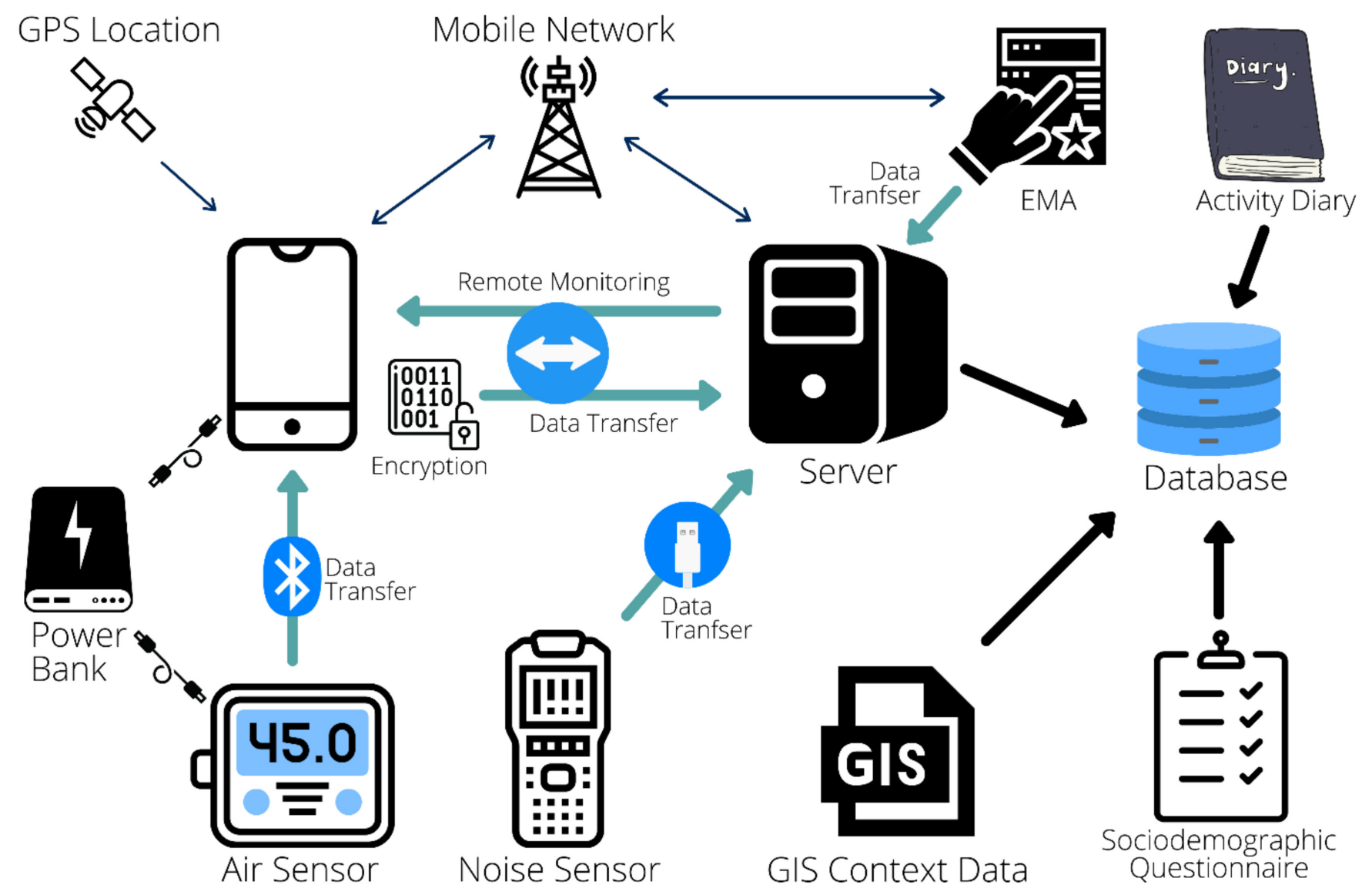

Figure 1. The system overview of the individual environmental exposure assessment system.

Although progress has been made in assessing individual-level environmental exposure, several issues still need to be addressed. First, existing studies have mainly focused on air pollution, with limited consideration of other environmental factors such as noise exposure. However, noise and air pollution may be closely related to similar sources and health impacts $[34,35]$. Further, exposure to air and noise pollution may have similar health effects on the human neurocognitive and cardiovascular systems [36-38]. Thus, considering only noise or air pollution may lead to misleading results in the relationships between environmental exposure and its health effects [34,36]. As sensor technologies for more accurate assessment of individual exposure to noise and air pollution become available, more studies are needed to further explore the synergistic relations between real-time noise and air exposure and the mechanisms of how they interact to impact human health.

In our pilot study conducted in Chicago, the integrated objective environmental exposure monitoring devices combine a GPS-equipped mobile phone, an air pollution sensor, and a noise sensor, with two additional power banks to provide extra battery life for the portable devices (Figure 2). The lightweight mobile phone served as a hub for data collection and is equipped with a GPS to collect real-time location data. The air pollution sensor was connected to the mobile phone via Bluetooth and transferred real-time air quality data to the phone's internal memory, while the mobile devices could be remotely accessed using the TeamViewer app, which helped the research team to monitor the status of both the GPS and the air pollution sensor (including battery usage and data collection status). When issues were discovered during remote monitoring, the research team could fix the problems remotely or call the participants to help solve the issues in real-time to avoid data loss as much as possible. The portable noise sensor ran independently and had enough internal memory to store the noise data for the entire data collection period. 


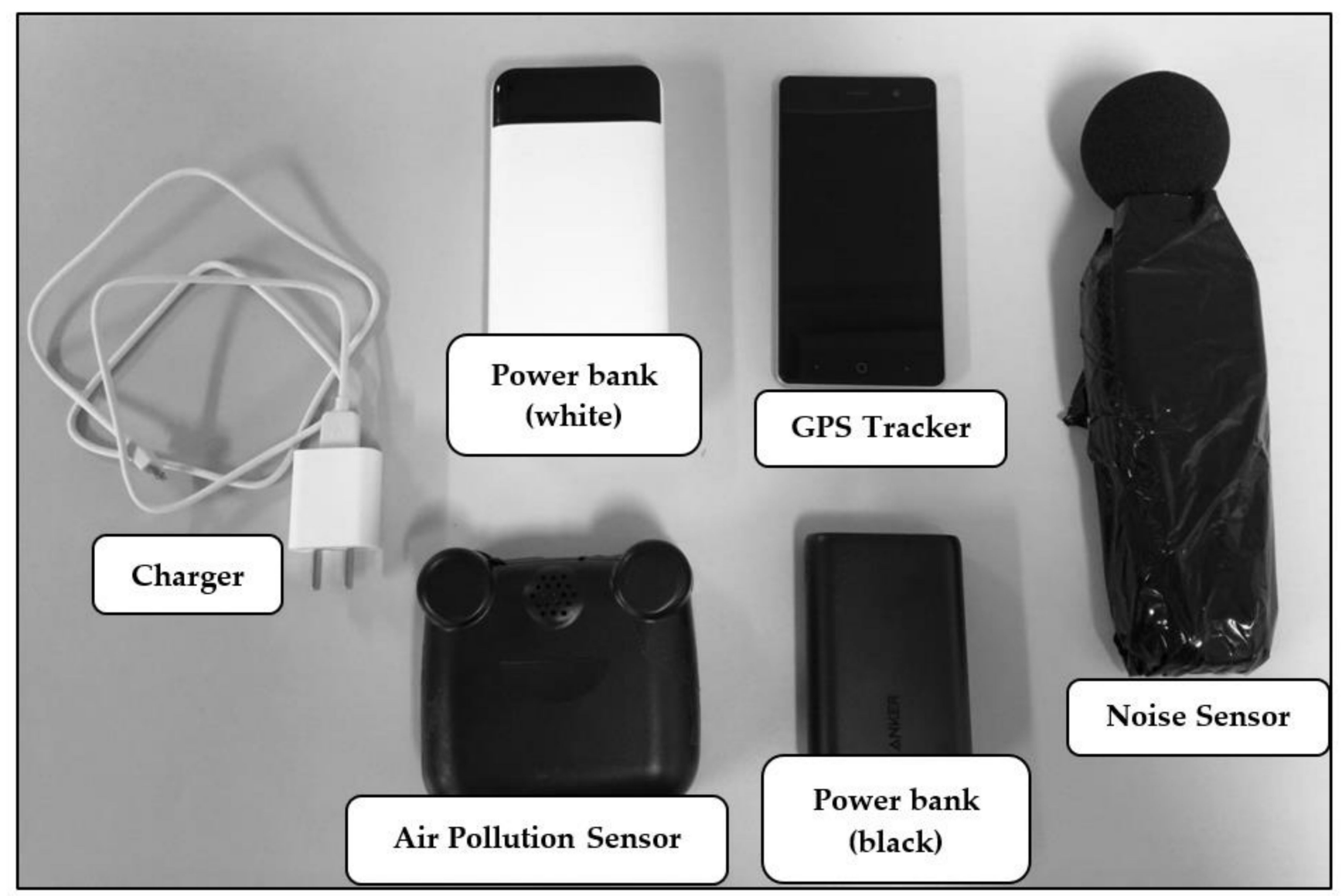

Figure 2. The GPS and portable sensing devices used in the study.

The configuration and settings of these portable devices are shown in Table 1. AirBeam (HabitatMap, Brooklyn, NY, USA) was selected as the portable air pollution sensor because of its light weight (198.5 g), long battery life (10 h if fully charged), and reasonable accuracy and precision of its $\mathrm{PM}_{2.5}$ measurements. The performance of AirBeam has been evaluated in many previous studies. In the field test performed by the Air Quality Sensor Performance Evaluation Center (AQ-SPEC) in the South Coast Air Quality Management District (SCAQMD, Diamond Bar, CA, USA), the measurements of $\mathrm{PM}_{2.5}$ (24-h mean) strongly correlated with Federal Equivalency Method (FEM) GRIMM monitor data $\left(R^{2}>0.89\right)$ [39]. Mukherjee et al. [40] compared three units of AirBeam against the GRIMM 11-R reference instrument and found that the measurements from AirBeam presented robust sensor-tosensor precision $\left(R^{2}=0.95-0.99\right)$ and moderate agreement with the reference measurements $\left(\mathrm{R}^{2}=0.66-0.71\right)$ over a range of different temperature and relative humidity at Cuyama Valley (CA, USA). Similar results were reported in a more recent study that deployed AirBeam at two sites in Sacramento (CA, USA) [41]. SLM-25 portable data-logging sound level meters were used for noise measurement in the study. The portable noise sensors logged the every-minute A-weighted decibels (dBA) of each participant's surrounding noise. It meets IEC61672 Type 2 and ANSI S1.4 Type 2 Sound Level Meter Standards (accuracy: +1.5 dB; measurement range: 30-130 dBA). To ensure accuracy, each noise sensor was calibrated using a CEM SC-05 Sound Level Calibrator at both C-weighted and A-weighted $94 \mathrm{~dB}$ and $114 \mathrm{~dB}$ before distribution to each participant. 
Table 1. The configuration and settings of the portable devices and software.

\begin{tabular}{|c|c|c|}
\hline Devices \& Software & Configuration & Data Collection \\
\hline Portable air pollution sensors & $\begin{array}{l}\text { AirBeam (PM2.5 in the unit of } \mu \mathrm{g} / \mathrm{m}^{3} \text {; } \\
2000 \mathrm{mAh})\end{array}$ & Air pollution data collection \\
\hline Portable noise sensors & $\begin{array}{c}\text { SLM-25 (accuracy: }+1.5 \mathrm{~dB} \text {; measurement } \\
\text { range: } 30-130 \mathrm{dBA} \text { ) }\end{array}$ & Noise data collection \\
\hline Mobile phone & $\begin{array}{l}\text { ZTE A603 (GPS with A-GPS support; } \\
16 \text { GB memory; } 2400 \text { mAh) }\end{array}$ & $\begin{array}{l}\text { Hub for GPS and air pollution data } \\
\text { collection and storage }\end{array}$ \\
\hline Power bank (white) & Aigo E20000+ (20,000 mAh) & $\begin{array}{l}\text { Provide extra battery life for the air } \\
\text { pollution sensor }\end{array}$ \\
\hline Power bank (black) & Anker PowerCore (10,000 mAh) & $\begin{array}{l}\text { Provide extra battery life for the } \\
\text { mobile phone }\end{array}$ \\
\hline GPS Logger & $\begin{array}{l}\text { Android application (installed on the } \\
\text { mobile phone) }\end{array}$ & GPS data collection. \\
\hline TeamViewer & $\begin{array}{l}\text { Android application \& Desktop software } \\
\text { (installed in the cellphone and remote } \\
\text { monitor computers) }\end{array}$ & Remote monitoring of the data collection \\
\hline AirCasting & $\begin{array}{l}\text { Android application (installed in } \\
\text { the cellphone) }\end{array}$ & $\begin{array}{l}\text { Communicating with the air } \\
\text { pollution sensor }\end{array}$ \\
\hline Secret Space Encryptor & $\begin{array}{l}\text { Android application \& Desktop software } \\
\text { (installed in the mobile phone and remote } \\
\text { monitor computers) }\end{array}$ & $\begin{array}{l}\text { Encrypting the GPS trajectory and air } \\
\text { pollution data in the mobile phone to } \\
\text { protect participants' privacy }\end{array}$ \\
\hline
\end{tabular}

The mobile phone (ZTE A603) worked as the data hub for the GPS and air pollution data, where the GPS trajectory data were recorded by GPS Logger (an Android application), and the air pollution data were stored using AirCasting (an Android application). It is equipped with a GPS with A-GPS support for accurate and reliable location tracking. The device's 16 GB memory is capable of storing one-week long's GPS trajectory and air pollution data. The mobile phone worked with TeamViewer (an Android application and desktop software) for the remote monitoring of the status of data collection and data uploading. The two extra power banks provided extra battery life for both the mobile phone and AirBeam to avoid data loss caused by an unexpected battery drain. For ease of use, we packed all the portable devices and the extra power banks in a device bag, as shown in Figure 3a. The air pollution sensors and noise sensors were installed in the two mesh pockets on the two sides of the bag (see Figure $3 b$ ) for good air ventilation and the prevention of sound blocking. The size of the mesh cell is relatively large, and we made sure the inlet was facing out for good air ventilation. The participants were asked to carry the bag all the time during the survey days.

In order to maintain the quality of data and minimize the chance of data loss due to technical issues, we utilize TeamViewer to monitor the data collection devices. The status of the devices and the data collection apps were checked through remote access with TeamViewer every $2 \mathrm{~h}$ (from 8 a.m. to $10 \mathrm{p} . \mathrm{m}$. every day) by members of the research team to make sure that all the devices are working well. When any device was found to have low battery power, the research team would either call or text the participants to recharge the device. If any device was found to be disconnected, the research team would call the participants to fix the problem. 


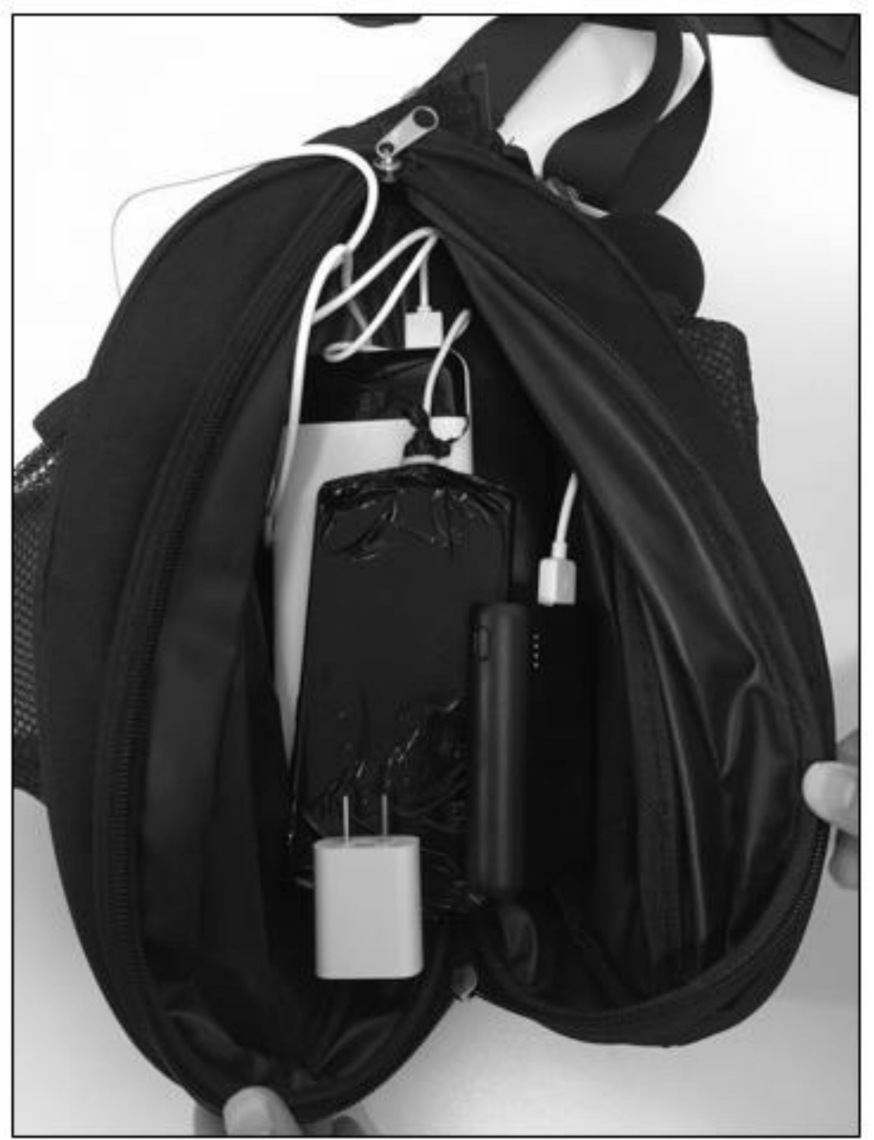

(a)

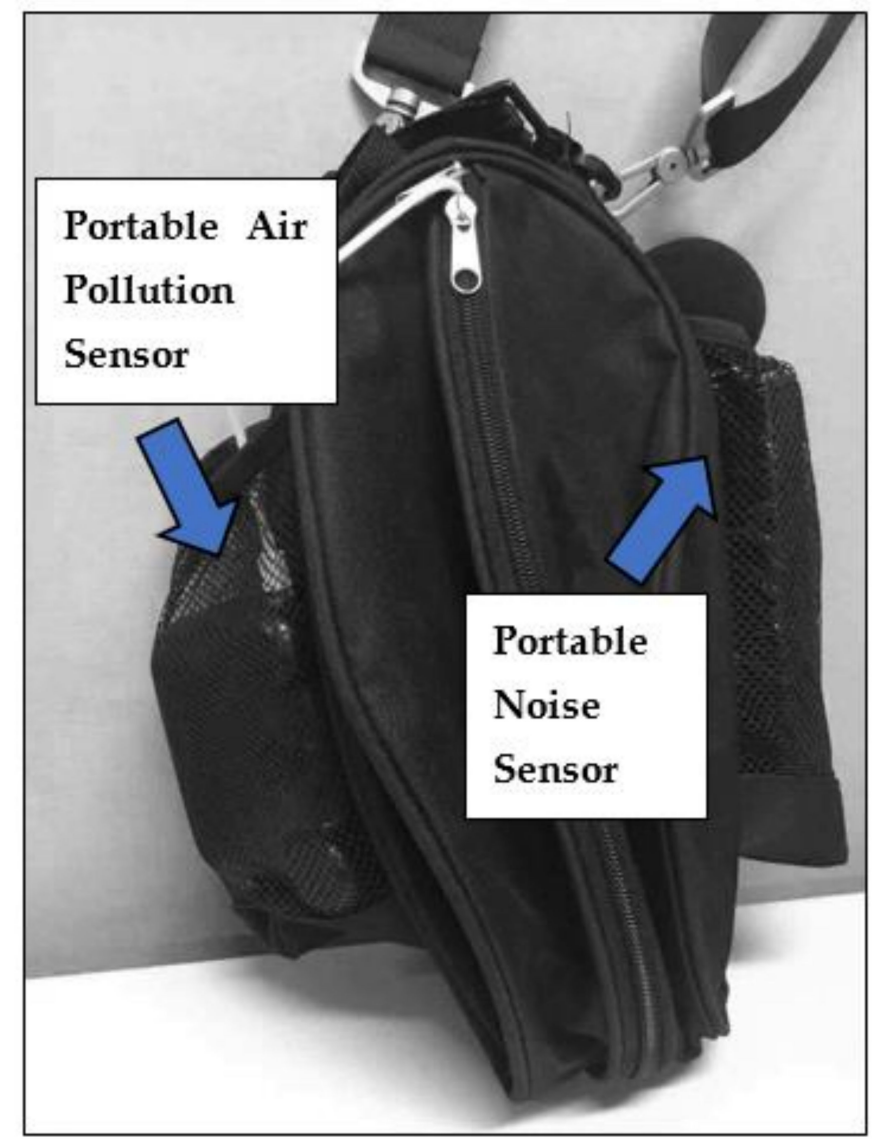

(b)

Figure 3. The device bag for the GPS and mobile sensors. (a) The portable devices are packed into a device bag; (b) air pollution sensors and noise sensors are placed in the two external mesh pockets on the two sides of the bag.

All data collected by the mobile phone, including GPS tracking and air pollution data, were encrypted in the phone using the open-source data encryption software Secret Space Encryptor (S.S.E.) for Android through remote control by TeamViewer. After the encryption, the data were transferred to the host server using the File transfer function of TeamViewer, while the raw data on the mobile phone was securely shredded. All the encrypted data were finally stored in one external hard disk (encrypted with BitLocker) and backed up in another external hard disk (encrypted with BitLocker). All data were not decrypted until they had been securely transferred to an encrypted (by BitLocker) and password-protected computer with no Internet access in a secure and locked room.

\subsection{Integrated Subjective Environmental Exposure Sensing Tool}

In addition to the objective data collected by GPS trackers and portable sensors, subjective exposures from participants were collected to understand the differences in perceived exposures among people with activity dairy and ecological momentary assessment data. Further, collecting and using data on perceived exposures allows for the triangulation and validation of data collected by multiple methods. This would help provide more accurate and reliable knowledge of the relationships between individuals' environmental exposure and its health impacts $[42,43]$.

In this study, all participants attended a briefing session at the collaborating organization. During the session, participants (1) went through the consent process, (2) completed the questionnaire, (3) were also trained on how to fill out the activity diary, including how to $\log$ specific events and trips, (4) were briefed on how ecological momentary assess- 
ment (EMA) text messages would appear in the mobile phones given to them and how to complete them promptly.

Activity diaries were an additional data source to assess individual exposure to environmental risks. They were a useful supplementary data source besides GPS trajectories [43]. Time geographers have frequently used the activity diary method to understand how individuals undertake their daily activities and trips within certain space-time constraints [44]. The activity diary method collects more contextual information about people's activities and trips $[45,46]$ and allows for more detailed delineations of people's microenvironments $[37,45]$. For instance, it can capture the details of different microenvironments such as residential locations, workplaces, recreational places, and transportation environments [47].

In this study, activity diaries were used to collect detailed information of each participant's daily activities and trips in sequence. Participants completed a 2-day activity diary (one on a weekend day and one on a weekday), in which they briefly logged each activity or trip they performed. For each activity and trip, participants were asked to record the start time, type of companion, space-time fixity (by rating whether the start time and the location can be changed easily), and their subjective evaluation of noise (by rating whether noise is a problem). In addition, for each activity, participants also logged the locations (whether the activity was at home, workplace, or other types of places) and the street addresses of all the locations recorded in their activity diaries, indoor/outdoor (whether the activity was undertaken indoor or outdoor), and the type of the activity. Activity type covers five categories, including work/study, personal affairs, housework, shopping, and recreation, together with other sub-categories in each category. Participants also reported their primary travel mode for each trip, including walking, biking, motorcycle, taxi, bus, subway, shuttle, car, and others. The data collected by the activity diaries were used to investigate the context of each activity. Further, the data collected by the activity diaries (e.g., start time, duration, the address of each activity location, and indoor/outdoor) were used to cross-validate the GPS trajectories.

Ecological momentary assessment (EMA) was another important component in our data collection effort to provide contextualized information. Previous studies have utilized EMA methods to examine issues such as people's physical activities, their situated physical and social contexts [48,49], emotional experiences such as moods, stress, and anxiety [50], environmental stressors [51], and health-related behaviors and symptoms as they occur in real-time [52,53]. Specifically, EMA helps provide real-time measurements of individuals' behavioral and psychological states in their natural environments [53]. In addition, repeated assessments in EMA can show fluctuations in environmental exposure over certain periods [51], which helps researchers understand how health-related behaviors and outcomes change over time and across contexts [54]. Further, the collection of EMA data together with GPS data $[20,55]$ not only enriches the EMA data with spatial information but also generates more contextualized information for the GPS data, providing insight into the complex relationships between environmental exposure and health outcomes.

In the Chicago project, EMA was used to collect real-time data of participants' environmental perceptions and health-related psychological stress. The data were collected with SurveySignal and SurveyMonkey. The configuration of the EMA collection software is provided in Table 2. Participants were requested to answer three short EMA questions: "How much does noise bother or disturb your current activity/trip?", "How much does air pollution bother or disturb your current activity/trip?", and "How stressed are you now?". Responses to each of these questions were provided on a 4-point scale: "not at all", "slightly", "moderately", and "extremely stressed". This project conducted a timebased EMA survey by sending survey messages to participants at 9 a.m., 12 p.m., 4 p.m., and 8 p.m., respectively, representing the morning, noon, afternoon, and evening of a day. Based on the specific time point of each EMA response from each participant, the contextualized data collected by the activity diaries and the spatiotemporal data collected by GPS were integrated for momentary environmental health analysis. 
Table 2. The configuration of the ecological momentary assessment (EMA) collection software.

\begin{tabular}{ccc}
\hline Devices and Software & Description & Data Collection \\
\hline SurveySignal & Survey distribution application & $\begin{array}{c}\text { Sending out time-based EMA texts with links of } \\
\text { the survey to participant's mobile phone }\end{array}$ \\
\hline SurveyMonkey & Online survey tools & Collecting and management EMA survey results \\
\hline
\end{tabular}

\subsection{Additional Sociodemographic Information and Environmental Context GIS Data}

Sociodemographic information was collected through questionnaires. During the briefing session, participants were guided to finish a 10-page long questionnaire. The questionnaire includes sections that collect participants' sociodemographic information, including personal, household, transportation, moving history, community, health, and meals and fitness habits. The personal and household sections contain questions about gender, age, race, education, marital status, employment, income, family size, and dependents. The transportation section provides general information on the ownership of the automobile and commuting habits. The moving history and community sections render a thorough depiction of subjects' historical and current living environments, comprising questions about their residence locations, conditions, and ownership, as well as the general information and their perception of the neighborhoods. In the health section, questions about their historical and current physical health issues and mental health conditions were included to provide relevant health-related information. The comprehensive information collected in the questionnaire, integrated with the objective and subjective environmental exposure sensing data, provided the health outcome variables for the composite analysis in environmental health studies.

GIS context data is critical for environmental health studies. It could serve as a source of background environmental context information, such as locations of green space and blue space, or as additional data for validation or triangulation with the objective exposure information, such as map matching GPS trajectories with road network data to improve GPS data quality. The needed contextual or environmental data depends on research questions. In this study, focusing on chronic and mental health issues, we collected GIS-based data on road networks, census, community survey, points of interest, land use, air pollution monitoring, transportation noise data, and so on. The environmental context GIS data were obtained from the national census bureau (e.g., US Census Bureau), local authority data portal (e.g., Chicago Data Portal), open-source GIS database (e.g., the OpenStreetMap.com), and other publicly available environmental data (e.g., the national transportation noise map).

\subsection{Data Collection in the Chicago Pilot Project}

We conducted an exploratory study to implement the proposed integrated individual environmental exposure assessment system (IEEAS). It was conducted in the Humboldt Park community of the Chicago Metropolitan Area from October to December 2017 (the Chicago dataset). This suburban community is undergoing a process of gentrification as middle-class residents move into it, while there is still a significant number of lowincome residents in the community who live in affordable public housing. We recruited 45 participants in the community with the assistance of the Latin United Community Housing Association (LUCHA), a non-profit organization that provides affordable housing for low-income residents.

All participants attended a briefing session to receive training on how to fill out the surveys and how to carry and use the portable sensors properly. Data collection lasted for a consecutive 7 days, including 5 weekdays and 2 weekend days, for each participant. First, participants completed a personal questionnaire. They also completed an activity diary for two designated survey days ( 1 weekday and 1 weekend day) in which they logged all activities and trips they performed. Second, participants carried at all times all the tracking and sensing devices in a dedicated device bag provided to them during the 7-day period. To reduce the participants' burden, all the devices were fully charged before giving 
them to the participants (the sensors could run for $48 \mathrm{~h}$ with a full charge). From Day 3 onwards (after the first $48 \mathrm{~h}$ ), participants needed to charge all devices at home in the evening before using them the next day. Third, at the end of the 7-day period, participants completed an activity space survey, which recorded the locations they visited during the 7-day period and the locations they regularly visited in a typical week or at least once a week (e.g., workplaces, shopping malls, supermarkets, and restaurants). Note that the results reported later in this paper are based on the 34 participants (from the original 45) who provided a valid home address and have adequate GPS trajectories for implementing the green space and noise exposure assessments. The sociodemographic characteristics of these participants are listed in Table 3. Other contextual or environmental data used in the study were obtained from the Chicago Data Portal, the OpenStreetMap geospatial dataset, and the US Bureau of Transportation Statistics.

Table 3. Descriptive statistics of the Chicago participants' sociodemographic characteristics.

\begin{tabular}{|c|c|c|}
\hline \multicolumn{2}{|c|}{ Sociodemographic Variables } & \multirow{2}{*}{$\begin{array}{c}\text { Proportion } \\
38.7 \%\end{array}$} \\
\hline Gender & Female & \\
\hline & Male & $61.3 \%$ \\
\hline \multirow{4}{*}{ Race } & White & $10 \%$ \\
\hline & African American & $42 \%$ \\
\hline & Latino/Hispanic & $42 \%$ \\
\hline & Other & $6 \%$ \\
\hline \multirow{4}{*}{ Education } & Elementary School & $7 \%$ \\
\hline & High School & $58 \%$ \\
\hline & College/University & $32 \%$ \\
\hline & Graduate School & $3 \%$ \\
\hline \multirow{2}{*}{ Maritial Status } & Married & $18 \%$ \\
\hline & Others & $82 \%$ \\
\hline \multirow{5}{*}{ Annual Income (USD) } & Less than 10,000 & $58 \%$ \\
\hline & $10,000-24,999$ & $19 \%$ \\
\hline & $25,000-49,999$ & $10 \%$ \\
\hline & $50,000-99,999$ & $10 \%$ \\
\hline & 100,000 or more & $3 \%$ \\
\hline
\end{tabular}

The proposed IEEAS had also been implemented to collect a larger dataset in Beijing, China (the Beijing dataset) from December 2017 to February 2018. 120 subjects were recruited from the Meiheyuan community for data collection using the same set-up as the Chicago Project using GPS tracking devices, portable air pollution, and noise sensors, EMA, activity diaries, and questionnaires. Meiheyuan is located in the northeast of Beijing and is a typical inner suburban community. It covers about 91,000 square meters with a total population of about 5000. Table 4 lists the descriptive statistics of the participants sociodemographic characteristics. 
Table 4. Descriptive statistics of the Beijing participants' sociodemographic characteristics.

\begin{tabular}{ccc}
\hline \multicolumn{2}{c}{ Sociodemographic Variables } & Proportion \\
\hline \multirow{2}{*}{ Gender } & Female & $49 \%$ \\
\cline { 2 - 3 } & Male & $51 \%$ \\
\hline \multirow{2}{*}{ Employment } & Employed & $77 \%$ \\
\cline { 2 - 3 } Maritial Status & Unemployed & $23 \%$ \\
\cline { 2 - 3 } & Married & $68 \%$ \\
\cline { 2 - 3 } & Oess than 180,000 & $32 \%$ \\
\cline { 2 - 3 } Annual Income (RMB) & $180,000-539,999$ & $13 \%$ \\
\cline { 2 - 3 } & $540,000-101,900$ & $49 \%$ \\
\hline & 102,000 or more & $25 \%$ \\
\hline
\end{tabular}

\section{Result and Discussion}

\subsection{Exploratory Analysis}

Using the Chicago dataset, we conduct some exploratory analysis and discuss successful research that used the proposed IEEAS. Focusing on participants' exposure to the noise environment, we compare the difference in individual exposures obtained by the proposed system and conventional methods. With the help of the IEEAS, we also examine the interactions among environmental factors and their complex associations with health. Thus, several examples of composite analysis with the data collected based on the IEEAS are further discussed to illustrate its advantages.

\subsubsection{Individual Noise Exposure Assessment}

People's noise exposure may vary across space and time in a dynamic and complex manner. Therefore, accurately measuring individual exposures to noise can be challenging. The standard measure of noise exposure is $L_{A e q, 24 h}$, the A-weighted equivalent continuous sound level over the $24 \mathrm{~h}$ of a day [56]. Based on the Chicago dataset, we assessed and compared individual exposure to noise using three measures: home-based $L_{A e q, 24 h}$, GPSbased $L_{A e q, 24 h}$, and sensor-based $L_{A e q, 24 h}$. First, home-based $L_{A e q, 24 h}$ is calculated based on the home location of each participant by overlaying it with the National Transportation Noise Map that models the approximate average noise energy due to traffic-related noise sources. The National Transportation Noise Map is obtained via the geospatial data portal of the Bureau of Transportation Statistics [57]. It was "developed using a 24-h equivalent sound level noise metric as of 19 April 2018" [58], which is very close to the data collection period of the Chicago Project. This is the average noise exposure for an individual based on his/her home location. It is calculated based on a static noise map and thus does not reflect the dynamic noise environment people are exposed to as they undertake their daily activities.

Second, based on participants' GPS tracking records, the $L_{A e q, 24 h}$ at the locations of each participant's GPS records are extracted by overlaying them with the national transportation noise map. Then, a time-weighted average of the noise exposure is calculated based on the extracted $L_{A e q, 24 h}$ values at all the GPS records. This is the GPS-based $L_{A e q, 24 h}$. Compared to the home-based measure, the GPS-based $L_{\text {Aeq, } 24 h}$ takes into account the spatial dynamics of people's daily activities and thus provides a better estimation of their overall noise exposure. However, the National Transportation Noise Map used to derive the GPSbased $L_{A e q, 24 h}$ values is still static and cannot incorporate the temporal dynamics of the noise environment. 
The third measure of individual exposure to noise in this study is based on the real-time data acquired by the portable noise sensors. It takes into account both the temporal dynamics of the noise environment and the spatial dynamics of people's daily activities. It is calculated using the noise level data collected from the noise sensors that recorded the different noise levels at different times and locations along with a participant's daily movement. The formula of $L_{A e q, 24 h}$ is used to calculate the A-weighted equivalent continuous sound level over a period of time T [56]. In this study, the sensor-based accumulated noise exposure $L_{\text {Aeq, } 24 h}$ is evaluated by considering both a weekday and a weekend day to better represent individuals' daily noise exposure levels as follows.

$$
L_{\text {Aeq, } T}=10 \lg \left(\frac{1}{T} \int_{0}^{T} 10^{0.1 L_{P A}} d t\right)
$$

Here, $L_{P A}$ is the one-minute A-weighted sound level (dBA) (on a logarithmic scale) recorded by the portable noise sensors.

The noise exposures obtained with these three measures (home-based $L_{A e q, 24 h}$, GPSbased $L_{A e q, 24 h}$, and sensor-based $L_{A e q, 24 h}$ ) are compared to illustrate their differences and highlight the new opportunities for evaluating individual exposures to dynamic environmental contexts. Figure 4 compares the three individual noise exposure measures: home-based $L_{A e q, 24 h}$, GPS-based $L_{A e q, 24 h}$, and sensor-based $L_{A e q, 24 h}$. In the figure, the horizontal axis represents the 34 participants in this analysis, while the vertical axis shows the values of the three measures of noise exposure. As indicated in the figure, individual noise exposures estimated by the three metrics are significantly different from each other.

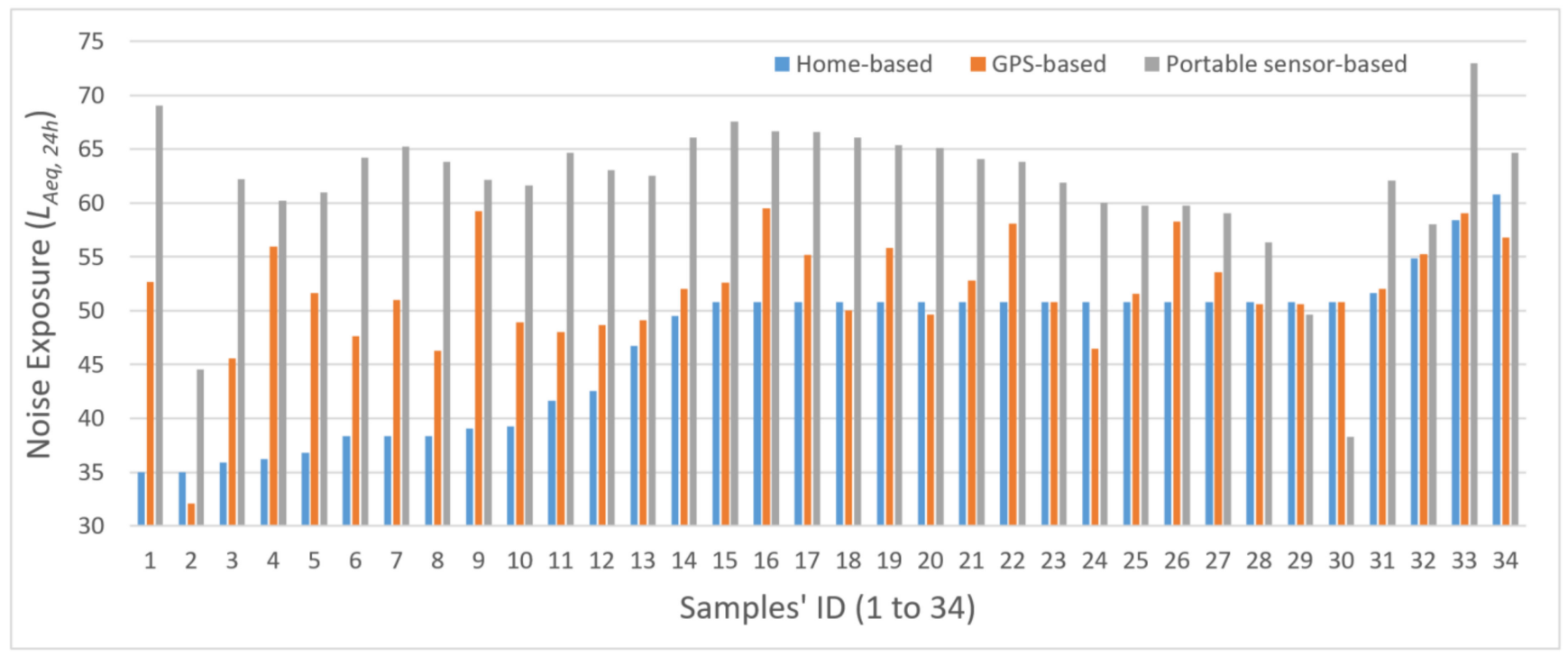

Figure 4. Comparison of individual noise exposure estimated by the three methods (home-based, GPS-based, and portable sensor-based) for each participant.

The differences in the individual noise exposure estimated by the three methods are further investigated with descriptive statistics and correlation analysis (Table 5), which shows that the sensor-based measure gives relatively high exposure values, while the home-based measure has relatively low assessments among the three methods. The homebased measure has the lowest mean (46.81) and the highest standard deviation (7.11), while the sensor-based measure gives the highest mean (61.71). It is worth noting that the individual noise exposures assessed by the home-based and GPS-based measures are significantly correlated $(p<0.01)$. In addition, the measures obtained by the GPS-based and sensor-based methods are also significantly correlated $(p=0.01)$. However, there is no significant association $(p>0.1)$ in individual noise exposures between the home-based and sensor-based measures. 
Table 5. Descriptive statistics and correlation between the three measures of individual noise exposure.

\begin{tabular}{|c|c|c|c|c|c|c|}
\hline & & Mean & Std. Deviation & Std. Error Mean & Correlation & $p$-Value \\
\hline \multirow{2}{*}{ Pair 1} & Home $L_{\text {Aeq, } 24 h}$ & 46.81 & 7.11 & 1.22 & \multirow{2}{*}{0.48} & \multirow{2}{*}{$<0.01$} \\
\hline & GPS $L_{A e q, 24 h}$ & 51.71 & 5.20 & 0.89 & & \\
\hline \multirow{2}{*}{ Pair 2} & Home $L_{\text {Aeq, } 24 h}$ & 46.81 & 7.11 & 1.22 & \multirow{2}{*}{0.08} & \multirow{2}{*}{0.64} \\
\hline & Portable $L_{\text {Aeq,24h }}$ & 61.71 & 6.59 & 1.13 & & \\
\hline \multirow{2}{*}{ Pair 3} & GPS $L_{A e q, 24 h}$ & 51.71 & 5.20 & 0.89 & \multirow{2}{*}{0.44} & \multirow{2}{*}{0.01} \\
\hline & Portable $L_{A e q, 24 h}$ & 61.71 & 6.59 & 1.13 & & \\
\hline
\end{tabular}

Notes: $N=34$; Home $L_{A e q, 24 h}$ : home-based individual noise exposure assessment metric; GPS $L_{\text {Aeq, } 24 h}$ : GPS trajectory-based individual noise exposure assessment metric; Portable $L_{A e q, 24 h}$ : portable sensor based individual noise exposure assessment metric.

Table 6 shows the results of the paired sample $t$-test, which compares the pairwise differences in individual noise exposure between the three measures. As shown in the table, all of the three pairs of noise exposure measures show significant differences. For Pair 1 (home-based versus GPS-based measures), noise exposure assessed by the home-based measure is less than the values obtained by the GPS-based measure $(p<0.01)$, and the differences are statistically significant. On average, participants' home-based exposure levels are 4.9 (95\% CI: 2.64, 7.16) units lower than their GPS-based exposure levels. For Pair 2 (home-based versus sensor-based measures), the noise exposures evaluated by the homebased measure are less than the values obtained by the sensor-based measure $(p<0.01)$, and the differences are statistically significant.

Table 6. Paired sample $t$-test between the three measures of individual noise exposure.

\begin{tabular}{|c|c|c|c|c|c|c|c|c|c|}
\hline & & \multicolumn{5}{|c|}{ Paired Differences } & \multirow{3}{*}{$\mathbf{t}$} & \multirow{3}{*}{ df } & \multirow{3}{*}{$p$-Value } \\
\hline & & \multirow{2}{*}{ Mean } & \multirow{2}{*}{ Std. Deviation } & \multirow{2}{*}{ Std. Error Mean } & \multicolumn{2}{|c|}{ 95\% Confidence Interval of the Difference } & & & \\
\hline & & & & & Lower & Upper & & & \\
\hline Pair 1 & $\begin{array}{l}\text { Home } L_{\text {Aeq }, 24 h} \\
\& G P S L_{A e q, 24 h}\end{array}$ & -4.90 & 6.48 & 1.11 & -7.16 & -2.64 & -4.41 & 33 & $<0.01$ \\
\hline Pair 2 & $\begin{array}{l}\text { Home } L_{\text {Aeq, } 24 h} \& \\
\text { Portable } L_{\text {Aeq, } 24 h}\end{array}$ & -14.90 & 9.28 & 1.59 & -18.14 & -11.67 & -9.36 & 33 & $<0.01$ \\
\hline Pair 3 & $\begin{array}{l}\text { GPS } L_{\text {Aeq, } 24 h} \& \\
\text { Portable } L_{\text {Aeq, } 24 h}\end{array}$ & -10.00 & 6.37 & 1.09 & -12.22 & -7.77 & -9.15 & 33 & $<0.01$ \\
\hline
\end{tabular}

On average, the home-based exposure levels are $14.9 L_{\text {Aeq. } 24 h}$ (95\% CI: 11.67, 18.14) units lower than the sensor-based exposure levels. For Pair 3 (GPS-based versus sensorbased measures), the noise exposures assessed by the GPS-based measure is significantly different from the ones assessed by the sensor-based method $(p<0.01)$ in that the GPS-based exposure levels are $10.00 L_{\text {Aeq, } 24 h}(95 \%$ CI: 7.77, 12.22) units lower than the sensor-based exposure levels on average.

It is clear from these results that individual noise exposures measured by the three methods are significantly different. As Table 5 indicates, the home-based measure has the lowest mean and highest standard deviation. Thus, it significantly underestimated individual exposures to noise. There are two possible reasons for this. First, the homebased measure is an averaged indicator of noise exposure for an individual based only on the person's home location, so the measure does not consider the spatial dynamics of people's daily activities. Studies have shown that people move around to perform various daily activities (e.g., work and shopping) and only spend a limited amount of time at home $[18,59,60]$. The residential neighborhood only partially captures people's exposure to noise and may thus lead to inaccurate measurement. Second, the home-based $L_{A e q, 24 h}$ is calculated based on the National Transportation Noise Map, which is an approximate average noise energy level based on transportation noise sources over a 24-h period. The noise map is an averaged indicator of ambient noise and is a static representation of 
noise distribution that does not consider the temporal variations in the noise environment. However, the noise environment is dynamic and constantly changing over time. Ignoring the temporal dynamics of the noise environment when assessing individual noise exposure may introduce bias. Furthermore, the National Transportation Noise Map only takes into account one source of noise (transport-related noise) while ignoring all other sources of noise (e.g., construction activities) that individuals may be exposed to in their daily activities [61].

Because the noise sensors precisely recorded the noise level in each participant's immediate environment in real-time at a high spatial and temporal resolution, the sensorbased measure gives the most accurate measurement of individual noise exposure. In addition, the noise sensors capture individual noise exposure at multiple locations, in various microenvironments, and at different times, such as sleeping at home at night, working at workplaces during work time, and commuting in the morning and late-afternoon rush hours. Further, the noise sensors can capture multiple sources of noise, including transportation, commercial activities, and construction activities. With the capability to consider both the spatial and temporal variations in noise level as well as human mobility, this method gives the most accurate measurement of individual exposure and thus helps mitigate the UGCoP and the NEAP in noise exposure assessment.

Interestingly, the range of noise exposure obtained by the sensor-based measure for most of the participants is from about 60 to $65 \mathrm{dBA}$ (with relatively small standard deviations), which is much smaller than the one measured by the home-based method (from about 38 to $51 \mathrm{dBA}$ ). A possible reason for this may be that the sensor-based measure considers human mobility. Thus, the overall noise exposure level is subject to neighborhood effect averaging (as a result of an averaging of the exposures at different locations for various daily activities).

As a manifestation of the neighborhood effect averaging problem (NEAP), the sensorbased exposure measurements among the participants would thus show smaller variation when compared to the home-based measurements [16]. Since the home-based measure considers only the home location, noise levels may vary significantly depending on the residential location of the participant. Thus, participants whose homes are located near major highways or airports would have much higher noise exposure when compared to those with homes in quiet or remote neighborhoods. Thoroughly considering all noise exposures at different activity locations, the sensor-based method provides a better estimation of individual noise exposure.

\subsubsection{Composite Environmental Health Analysis}

Integrating objective exposure monitoring and subjective exposure sensing helps us understand the complex pathways of environmental effects on health. For instance, integrating GPS trajectories and activity dairies promotes our understanding of individual mobility and activity space analysis [62]; integrating GPS trajectories, air pollution sensor data, and environmental context data enrich our understanding of individual air pollution exposure and its relationship with environmental contexts as well as health outcomes [22]; integrating GPS trajectories, noise sensor data, and environmental context data enhances our understanding individual noise exposure and its relationship with health [61]. In what follows, we further discuss and highlight the advantages of using composite analysis based on three studies that used the dataset collected in Beijing with the IEEAS (the Beijing dataset).

Ma et al. [22] investigated the relationship between individuals' socioeconomic status and their ability to avoid air pollution exposure through daily mobility based on the Beijing dataset. In the study, indoor and outdoor air pollution exposure can be distinguished by integrating the data of portable air pollution sensors, GPS tracking, and activity dairies (participants indicated whether activities happened indoor or outdoor). By comparing the air pollution exposures participants' experienced in indoor or outdoor locations, the study found significant evidence of neighborhood effect averaging in air pollution exposure 
assessment and explored whether the air pollution exposures of different social groups can be mitigated by changing mobility patterns. The study shows that data collected with the IEEAS can provide a much more accurate and refined picture of individual exposure to air pollution exposure and how the NEAP may be mitigated.

Using the integrated approach of the IEEAS and the Beijing dataset, Kou et al. [61] examined the direct and indirect effects of context, momentary measured noise, and perceived noise on individual psychological stress levels. The study found that momentary measured noise influences psychological stress through the mediating effect of perceived noise, and different activity, travel, social, and temporal contexts significantly influence people's momentary measured noise, perceived noise, and psychological stress. These findings greatly enhance our understanding of how the relationship between individual noise exposure and psychological health is influenced by perceived noise and context at a high spatiotemporal resolution.

Similarly, Ma et al.'s [63] study assessed individual noise exposure and its relationship with mental health using the Beijing dataset. The study compared the noise exposure assessed by the integrated approach based on the IEEAS with the conventional static residence-based approach. The study explored how individual noise exposures differ among various daily activities and travel modes and how those exposures varied between workdays and weekends. With composite analysis, the research further examined the noise exposure effects on mental health and found that noise exposure in different activity contexts has various associations with individual mental health.

\subsection{Limitations and Future Direction}

The Chicago and Beijing Projects reported in this paper have several limitations that should be addressed in future research. First, the sample sizes are relatively small. Collecting data from larger samples is necessary to provide further evidence on the relative strengths of different exposure measurement methods. Second, the data were collected from one urban community in Chicago and Beijing separately, which limits the generalizability of the framework to other locations with different social and physical environments (e.g., rural communities). Future studies should be conducted in various cities or countries that cover larger areas. Third, we used the datasets to perform only limited analysis. However, more studies using other integrated approaches are necessary for thoroughly exploring this kind of integrated system and generating new insights. Additionally, new analytical approaches should be developed based on the proposed IEEAS in future environmental health studies. Fourth, although the air pollution sensors used in this study were factory-calibrated, they were not calibrated in the Chicago Pilot Project before its deployment. Because sensor measurements can be biased due to relative humidity and temperature, future studies should evaluate the meteorological impacts and adjust raw measurements using correction algorithms [64]. We chose AirBeam 1 because it has reasonable performance according to the literature and has important features needed for the project, such as portability and reasonable price. In addition, when this study was performed, AirBeam1 was the most widely used portable sensor that had several evaluation results. However, AirBeam1 is only one example that can be integrated into the IEEAS. Therefore, it can be replaced with a newer version (AirBeam2) or other portable air sensors that provide higher accuracy, precision, and reliability depending on the study purpose. Fifth, the accuracy of the GPS tracking data may be constrained by the tracking device used in this study. In addition, accuracy may vary from location to location due to the urban canyon effect. Nevertheless, in the Chicago Project, tracking inaccuracy due to urban canyons in the study area is minimal because it is a suburban area in Chicago where all buildings are low and the streets are wide. In addition, GPS tracking devices can be easily replaced with the latest version that provides higher accuracy depending on the specific need of study. Lastly, we installed the air pollution sensor in a side mesh pocket, which may result in potential $\mathrm{PM}_{2.5}$ sample loss. Although the inlet was facing out for good air ventilation when setting up the device in a mesh pocket, in future studies, it would be better to set up the inlet of the air 
sensor without any obstruction to minimize this potential issue. Note that it is possible to integrate other portable devices into the IEEAS for more comprehensive exposure assessments. Other mobile devices such as accelerometers, thermometers, hygrometers, and heart rate monitors could be integrated into the system. Future studies are necessary to investigate the feasibility of integrating these other portable devices for environmental exposure assessment.

\section{Conclusions}

In this study, we proposed an individual environmental exposure assessment system (IEEAS) that integrates the objective monitoring devices and subjective sensing tools, as well as sociodemographic information and environmental context GIS data, to provide a composite way for individual-based environmental exposure data collection for environmental health studies. The IEEAS integrated objective and subjective data collected in real-time provide fine-grained, spatially, and temporally situated data about the measured environmental context, personal activity, and individual perception. The key measurements in the data collection process include the levels of noise or air pollutants $\left(\mathrm{PM}_{2.5}\right)$ in real-time as measured by the portable sensors, the subjective assessments of the levels of noise or air pollutants, and the levels of stress reported by the participants via the EMA prompts received on their mobile phones, and details of participants' activities and trips on the survey days (e.g., the start time, end time and duration of each activity and trip, the address of each activity location, and whether an activity was conducted in an indoor or outdoor environment) recorded by the activity diaries, which in turn can be used to cross-validate the GPS trajectories. In addition, data in the activity diaries can be used to identify participants' microenvironments (e.g., workplaces, shopping malls, supermarkets, and restaurants).

This integrated assessment system enables linking empirically measured or sensed environmental characteristics with participants' activities and momentary experiences to validate, differentiate, and augment sensed data with actual activities and emotional responses to more clearly understand the interrelatedness of measured and experienced real-time environments. Further, the IEEAS enables researchers to capture accurate individual exposure to environmental risks in different microenvironments, involving the risks from diverse sources, at different geographic locations and times, and in both the outdoor and indoor environments. With the capability to consider both the spatial and temporal variations in environmental risks as well as human mobility, the IEEAS also helps mitigate the UGCoP and the NEAP in environmental exposure assessment. It yields relatively accurate measurements of individual exposure in a composite way and presents new opportunities for developing more sophisticated ways to measure individual environmental exposure, and thus promotes a better understanding of the relationship between individual environmental exposure and health outcomes.

Author Contributions: Conceptualization, J.W., L.K. and M.-P.K.; methodology, J.W., L.K., M.-P.K., R.M.S., K.L. and Y.M.P.; formal analysis, J.W. and L.K.; data curation, J.W., L.K., M.-P.K., R.M.S., K.L. and Y.M.P.; writing-original draft preparation, J.W., L.K. and M.-P.K.; writing-review and editing, J.W., L.K. and M.-P.K.; project administration, M.-P.K.; funding acquisition, J.W. and M.-P.K. All authors have read and agreed to the published version of the manuscript.

Funding: J.W. was supported by grants from the University of Toronto (UTM Bridge Funding). M.-P.K. was supported by grants from the Hong Kong Research Grants Council (General Research Fund Grant no. 14605920; Collaborative Research Fund Grant no. C4023-20GF) and a grant from the Research Committee on Research Sustainability of Major Research Grants Council Funding Schemes of the Chinese University of Hong Kong.

Institutional Review Board Statement: The study was conducted according to the guidelines of the Declaration of Helsinki, and approved by the Institutional Review Board (IRB) of the University of Illinois at Urbana-Champaign (IRB protocol number 18198; 19 October 2017).

Informed Consent Statement: Informed consent was obtained from all subjects involved in the study. 
Data Availability Statement: The data collected in the study cannot be shared because there is no feasible method for sharing the high-resolution georeferenced (e.g., GPS) data collected without compromising the participants' privacy.

Acknowledgments: The authors thank Yanwei Chai and his research team (Xinlin Ma and Xue Zhang) from Peking University, and Rachael Wilson and the Latin United Community Housing Association (LUCHA) in Chicago for their help in subject recruitment and the briefing sessions. The assistance of Ruoxin $\mathrm{Li}$ in the data collection effort and the support of the TeamViewer for providing the remote access service during data collection are also gratefully acknowledged. The authors also thank the participants for their participation in the study and the anonymous reviewers for their helpful comments.

Conflicts of Interest: The authors declare no conflict of interest.

\section{References}

1. Seliske, L.M.; Pickett, W.; Boyce, W.F.; Janssen, I. Association between the food retail environment surrounding schools and overweight in Canadian youth. Public Health Nutr. 2009, 12, 1384. [CrossRef] [PubMed]

2. Chaix, B. Geographic Life Environments and Coronary Heart Disease: A Literature Review, Theoretical Contributions, Methodological Updates, and a Research Agenda. Annu. Rev. Public Health 2009, 30, 81-105. [CrossRef] [PubMed]

3. Koohsari, M.J.; Mavoa, S.; Villianueva, K.; Sugiyama, T.; Badland, H.; Kaczynski, A.T.; Owen, N.; Giles-Corti, B. Public open space, physical activity, urban design and public health: Concepts, methods and research agenda. Health Place 2015, 33, 75-82. [CrossRef] [PubMed]

4. Sallis, J.F.; Cerin, E.; Conway, T.L.; Adams, M.A.; Frank, L.D.; Pratt, M.; Salvo, D.; Schipperijn, J.; Smith, G.; Cain, K.L.; et al. Physical activity in relation to urban environments in 14 cities worldwide: A cross-sectional study. Lancet 2016, 387, $2207-2217$. [CrossRef]

5. Shareck, M.; Kestens, Y.; Vallée, J.; Datta, G.; Frohlich, K.L.; Vallee, J.; Datta, G.; Frohlich, K.L. The added value of accounting for activity space when examining the association between tobacco retailer availability and smoking among young adults. Tob. Control 2015, 25, 1-7. [CrossRef]

6. Kwan, M.-P.; Kenda, L.L.; Wewers, M.E.; Ferketich, A.K.; Klein, E.G. Sociogeographic context, protobacco advertising, and smokeless tobacco usage in the Appalachian Region of Ohio (USA). In Proceedings of the International Medical Geography Symposium, Durham, UK, 10-15 July 2011.

7. $\quad$ Epstein, D.H.; Tyburski, M.; Craig, I.M.; Phillips, K.A.; Jobes, M.L.; Vahabzadeh, M.; Mezghanni, M.; Lin, J.L.; Furr-Holden, C.D.M.; Preston, K.L. Real-time tracking of neighborhood surroundings and mood in urban drug misusers: Application of a new method to study behavior in its geographical context. Drug Alcohol Depend. 2014, 134, 22-29. [CrossRef]

8. Fowler, P.J.; Tompsett, C.J.; Braciszewski, J.M.; Jacques-Tiura, A.J.; Baltes, B.B. Community violence: A meta-analysis on the effect of exposure and mental health outcomes of children and adolescents. Dev. Psychopathol. 2009, 21, 227. [CrossRef]

9. Curtis, S. Space, Place and Mental Health; Ashgate Publishing Ltd.: London, UK, 2010; ISBN 0754673316.

10. Kwan, M.-P. The limits of the neighborhood effect: Contextual uncertainties in geographic, environmental health, and social science research. Ann. Am. Assoc. Geogr. 2018, 108, 1482-1490. [CrossRef]

11. Kim, J.; Kwan, M.-P. Beyond commuting: Ignoring individuals' activity-travel patterns may lead to inaccurate assessments of their exposure to traffic congestion. Int. J. Environ. Res. Public Health 2018, 16, 89. [CrossRef]

12. Zhao, P.; Kwan, M.P.; Zhou, S. The uncertain geographic context problem in the analysis of the relationships between obesity and the built environment in Guangzhou. Int. J. Environ. Res. Public Health 2018, 15, 308. [CrossRef]

13. Schwanen, T.; Wang, D. Well-being, context, and everyday activities in space and time. Ann. Assoc. Am. Geogr. 2014, 104, 833-851. [CrossRef]

14. Buck, C.; Kneib, T.; Tkaczick, T.; Konstabel, K.; Pigeot, I. Assessing opportunities for physical activity in the built environment of children: Interrelation between kernel density and neighborhood scale. Int. J. Health Geogr. 2015, 14, 1-16. [CrossRef]

15. Wang, J.; Lee, K.; Kwan, M.-P. Environmental influences on leisure-time physical inactivity in the US: An exploration of spatial non-stationarity. ISPRS Int. J. Geo-Inf. 2018, 7, 143. [CrossRef]

16. Kwan, M.-P. The neighborhood effect averaging problem (NEAP): An elusive confounder of the neighborhood effect. Int. J. Environ. Res. Public Health 2018, 15, 1841. [CrossRef]

17. Kwan, M.-P. The uncertain geographic context problem. Ann. Assoc. Am. Geogr. 2012, 102, 958-968. [CrossRef]

18. Kwan, M.-P. Beyond space (as we knew it): Toward temporally integrated geographies of segregation, health, and accessibility. Ann. Assoc. Am. Geogr. 2013, 103, 1078-1086. [CrossRef]

19. Park, Y.M.; Kwan, M.-P. Individual exposure estimates may be erroneous when spatiotemporal variability of air pollution and human mobility are ignored. Health Place 2017, 43, 85-94. [CrossRef]

20. Kwan, M.-P. How GIS can help address the uncertain geographic context problem in social science research. Ann. GIS 2012, 18, 245-255. [CrossRef]

21. Ma, J.; Li, C.; Kwan, M.; Kou, L.; Chai, Y. Assessing personal noise exposure and its relationship with mental health in Beijing based on individuals ' space-time behavior. Environ. Int. 2020, 139, 105737. [CrossRef] 
22. Ma, X.; Li, X.; Kwan, M.-P.; Chai, Y. Who could not avoid exposure to high levels of residence-based pollution by daily mobility? Evidence of air pollution exposure from the perspective of the neighborhood effect averaging problem (NEAP). Int. J. Environ. Res. Public Health 2020, 17, 1223. [CrossRef]

23. Browning, M.; Lee, K. Within what distance does "greenness" best predict physical health? A systematic review of articles with GIS buffer analyses across the lifespan. Int. J. Environ. Res. Public Health 2017, 14, 675. [CrossRef] [PubMed]

24. Mitchell, C.A.; Clark, A.F.; Gilliland, J.A. Built environment influences of children's physical activity: Examining differences by neighbourhood size and sex. Int. J. Environ. Res. Public Health 2016, 13, 130. [CrossRef] [PubMed]

25. Wang, J.; Kwan, M.-P. An analytical framework for integrating the spatiotemporal dynamics of environmental context and individual mobility in exposure assessment: A study on the relationship between food environment exposures and body weight. Int. J. Environ. Res. Public Health 2018, 15, 2022. [CrossRef] [PubMed]

26. Kwan, M.-P.; Wang, J.; Tyburski, M.; Epstein, D.H.; Kowalczyk, W.J.; Preston, K.L. Uncertainties in the geographic context of health behaviors: A study of substance users' exposure to psychosocial stress using GPS data. Int. J. Geogr. Inf. Sci. 2019, 33, 1176-1195. [CrossRef]

27. Kerr, J.; Duncan, S.; Schipperjin, J. Using global positioning systems in health research: A practical approach to data collection and processing. Am. J. Prev. Med. 2011, 41, 532-540. [CrossRef]

28. Steinle, S.; Reis, S.; Sabel, C.E. Quantifying human exposure to air pollution: Moving from static monitoring to spatio-temporally resolved personal exposure assessment. Sci. Total Environ. 2013, 443, 184-193. [CrossRef]

29. Chaix, B.; Méline, J.; Duncan, S.; Merrien, C.; Karusisi, N.; Perchoux, C.; Lewin, A.; Labadi, K.; Kestens, Y. GPS tracking in neighborhood and health studies: A step forward for environmental exposure assessment, A step backward for causal inference? Health Place 2013, 21, 46-51. [CrossRef]

30. Van der Spek, S.; Van Schaick, J.; De Bois, P.; De Haan, R. Sensing Human Activity: GPS Tracking. Sensors 2009, 9, $3033-3055$. [CrossRef]

31. Honicky, R.; Brewer, E.A.; Paulos, E.; White, R. N-SMARTS: Networked suite of mobile atmospheric real-time sensors. In Proceedings of the Second ACM SIGCOMM Workshop on Networked Systems for Developing Regions, Seattle, WA, USA, 18 August 2008; pp. 1-5.

32. Dutta, P.; Aoki, P.M.; Kumar, N.; Mainwaring, A.; Myers, C.; Willett, W.; Woodruff, A. Common Sense: Participatory urban sensing using a network of handheld air quality monitors. In Proceedings of the 7th ACM Conference on Embedded Networked Sensor Systems, Berkeley, CA, USA, 4-6 November 2009; pp. 349-350.

33. Kanjo, E.; Benford, S.; Paxton, M.; Chamberlain, A.; Fraser, D.S.; Woodgate, D.; Crellin, D.; Woolard, A. MobGeoSen: Facilitating personal geosensor data collection and visualization using mobile phones. Pers. Ubiquitous Comput. 2008, 12, 599-607. [CrossRef]

34. Foraster, M.; Künzli, N.; Aguilera, I.; Rivera, M.; Agis, D.; Vila, J.; Bouso, L.; Deltell, A.; Marrugat, J.; Ramos, R.; et al. High blood pressure and long-term exposure to indoor noise and air pollution from road traffic. Environ. Health Perspect. 2014, 122, 1193-1200. [CrossRef]

35. Künzli, N.; Kaiser, R.; Medina, S.; Studnicka, M.; Chanel, O.; Filliger, P.; Herry, M.; Horak, F.; Puybonnieux-Texier, V.; Quénel, P.; et al. Public-health impact of outdoor and traffic-related air pollution: A European assessment. Lancet 2000, 356, 795-801. [CrossRef]

36. Caspi, C.E.; Sorensen, G.; Subramanian, S.V.; Kawachi, I. The local food environment and diet: A systematic review. Health Place 2012, 18, 1172-1187. [CrossRef]

37. Steinle, S.; Reis, S.; Sabel, C.E.; Semple, S.; Twigg, M.M.; Braban, C.F.; Leeson, S.R.; Heal, M.R.; Harrison, D.; Lin, C.; et al. Personal exposure monitoring of PM2.5 in indoor and outdoor microenvironments. Sci. Total Environ. 2015, 508, 383-394. [CrossRef] [PubMed]

38. Tzivian, L.; Dlugaj, M.; Winkler, A.; Weinmayr, G.; Hennig, F.; Fuks, K.B.; Vossoughi, M.; Schikowski, T.; Weimar, C.; Erbel, R.; et al. Long-term air pollution and traffic noise exposures and mild cognitive impairment in older adults: A cross-sectional analysis of the Heinz Nixdorf recall study. Environ. Health Perspect. 2016, 124, 1361-1368. [CrossRef]

39. AQ-SPEC Air Quality Sensor Performance Evaluation Center Field Evaluation AirBeam PM Sensor. Available online: http:/ /www. aqmd.gov / docs / default-source/aq-spec/field-evaluations/airbeam---field-evaluation.pdf?sfvrsn=4 (accessed on 1 May 2021).

40. Mukherjee, A.; Stanton, L.G.; Graham, A.R.; Roberts, P.T. Assessing the utility of low-cost particulate matter sensors over a 12-week period in the Cuyama valley of California. Sensors 2017, 17, 1805. [CrossRef] [PubMed]

41. Mukherjee, A.; Brown, S.G.; McCarthy, M.C.; Pavlovic, N.R.; Stanton, L.G.; Snyder, J.L.; D’Andrea, S.; Hafner, H.R. Measuring spatial and temporal PM2.5 variations in Sacramento, California, communities using a network of low-cost sensors. Sensors 2019, 19, 4701. [CrossRef] [PubMed]

42. Crosbie, T. Using Activity Diaries: Some Methodological Lessons. J. Res. Pract. 2006, 2, 1-13.

43. Stewart, O.T.; Moudon, A.V.; Fesinmeyer, M.D.; Zhou, C.; Saelens, B.E. The association between park visitation and physical activity measured with accelerometer, GPS, and travel diary. Health Place 2016, 38, 82-88. [CrossRef]

44. Kajsa Ellegård A time-geographical approach to the study of everyday life of individuals-A challenge of complexity. GeoJournal 1999, 48, 167-175. [CrossRef]

45. Chen, J.; Shaw, S.L.; Yu, H.; Lu, F.; Chai, Y.; Jia, Q. Exploratory data analysis of activity diary data: A space-time GIS approach. J. Transp. Geogr. 2011, 19, 394-404. [CrossRef] 
46. Schweizer, C.; Edwards, R.D.; Bayer-Oglesby, L.; Gauderman, W.J.; Ilacqua, V.; Juhani Jantunen, M.; Lai, H.K.; Nieuwenhuijsen, M.; Künzli, N. Indoor time-microenvironment-activity patterns in seven regions of Europe. J. Expo. Sci. Environ. Epidemiol. 2007, 17, 170-181. [CrossRef]

47. Dons, E.; Int Panis, L.; Van Poppel, M.; Theunis, J.; Willems, H.; Torfs, R.; Wets, G. Impact of time-activity patterns on personal exposure to black carbon. Atmos. Environ. 2011, 45, 3594-3602. [CrossRef]

48. Maher, J.P.; Dzubur, E.; Huh, J.; Intille, S.; Dunton, G.F. Within-Day Time-Varying Associations Between Behavioral Cognitions and Physical Activity in Adults. J. Sport Exerc. Psychol. 2016, 38, 423-434. [CrossRef]

49. Seidman, M.D.; Standring, R. Noise and Quality of Life. Int. J. Environ. Res. Public Health 2010, 7, 3730-3738. [CrossRef]

50. Kashdan, T.B.; Collins, R.L. Social anxiety and the experience of positive emotion and anger in everyday life: An ecological momentary assessment approach. Anxiety Stress Coping 2010, 23, 259-272. [CrossRef]

51. Smyth, J.M.; Wonderlich, S.A.; Sliwinski, M.J.; Crosby, R.D.; Engel, S.G.; Mitchell, J.E.; Calogero, R.M. Ecological momentary assessment of affect, stress, and binge-purge behaviors: Day of week and time of day effects in the natural environment. Int. J. Eat. Disord. 2009, 42, 429-436. [CrossRef]

52. Moskowitz, D.S.; Young, S.N. Ecological momentary assessment: What it is and why it is a method of the future in clinical psychopharmacology. J. Psychiatry Neurosci. 2006, 31, 13-20.

53. Shiffman, S. Ecological Momentary Assessment (EMA) in Studies of Substance Use. Psychol. Assess. 2009, 21, 486-497. [CrossRef]

54. Shiffman, S.; Stone, A.A.; Hufford, M.R. Ecological Momentary Assessment. Annu. Rev. Clin. Psychol. 2008, 4, 1-32. [CrossRef] [PubMed]

55. Mitchell, J.T.; Schick, R.S.; Hallyburton, M.; Dennis, M.F.; Kollins, S.H.; Beckham, J.C.; McClernon, F.J. Combined Ecological Momentary Assessment and Global Positioning System Tracking to Assess Smoking Behavior: A Proof of Concept Study. J. Dual Diagn. 2014, 10, 19-29. [CrossRef]

56. Passchier-Vermeer, W.; Passchier, W.F. Noise exposure and public health. Environ. Health Perspect. 2000, 108, 123-131. [PubMed]

57. Bureau of Transportation Statistics National Transportation Noise Map. Available online: https://www.bts.gov/geospatial/ national-transportation-noise-map (accessed on 1 May 2021).

58. Bureau of Transportation Statistics CONUS Road and Aviation Noise Image Service. Available online: https://hub.arcgis.com/ datasets / 07fd10540182495db6261317a154443e (accessed on 1 May 2021).

59. Basta, L.A.; Richmond, T.S.; Wiebe, D.J. Neighborhoods, daily activities, and measuring health risks experienced in urban environments. Soc. Sci. Med. 2010, 71, 1943-1950. [CrossRef] [PubMed]

60. Wiehe, S.E.; Hoch, S.C.; Liu, G.C.; Carroll, A.E.; Wilson, J.S.; Fortenberry, J.D. Adolescent Travel Patterns: Pilot Data Indicating Distance from Home Varies by Time of Day and Day of Week. J. Adolesc. Health 2008, 42, 418-420. [CrossRef] [PubMed]

61. Kou, L.; Tao, Y.; Kwan, M.-P.; Chai, Y. Understanding the relationships among individual-based momentary measured noise, perceived noise, and psychological stress: A geographic ecological momentary assessment (GEMA) approach. Health Place 2020, 64, 102285. [CrossRef]

62. Wang, J.; Kwan, M.-P.; Chai, Y. An innovative context-based crystal-growth activity space method for environmental exposure assessment: A study using GIS and GPS trajectory data collected in Chicago. Int. J. Environ. Res. Public Health 2018, 15, 703. [CrossRef]

63. Ma, J.; Tao, Y.; Kwan, M.-P.; Chai, Y. Assessing mobility-based real-time air pollution exposure in space and time using smart sensors and GPS trajectories in Beijing. Ann. Am. Assoc. Geogr. 2020, 110, 434-448. [CrossRef]

64. Magi, B.I.; Cupini, C.; Francis, J.; Green, M.; Hauser, C. Evaluation of PM2. 5 measured in an urban setting using a low-cost optical particle counter and a Federal Equivalent Method Beta Attenuation Monitor. Aerosol Sci. Technol. 2020, 54, 147-159. [CrossRef] 